\title{
RESEARCH
}

\section{Targeting PDZ-binding kinase is anti-tumorigenic in novel preclinical models of ACC}

\author{
Adwitiya Kar1, Yu Zhang1, Betelehem W Yacob2, Jordan Saeed1, Kenneth D Tompkins1, Stacey M Bagby², \\ Todd M Pitts' ${ }^{2}$, Hilary Somerset ${ }^{3}$, Stephen Leong2, Margaret E Wierman ${ }^{1,4}$ and Katja Kiseljak-Vassiliades ${ }^{1,4}$ \\ 'Division of Endocrinology, Metabolism and Diabetes, Department of Medicine, University of Colorado School of Medicine, Anschutz Medical Campus, \\ Aurora, Colorado, USA \\ 2Division of Medical Oncology, Department of Medicine, University of Colorado School of Medicine, Anschutz Medical Campus, Aurora, Colorado, USA \\ ${ }^{3}$ Department of Pathology, University of Colorado School of Medicine, Anschutz Medical Campus, Aurora, Colorado, USA \\ ${ }^{4}$ Research Service, Rocky Mountain Regional Veterans Affairs Medical Center, Aurora, Colorado, USA
}

Correspondence should be addressed to K Kiseljak-Vassiliades: katja.kiseljak-vassiliades@ucdenver.edu

\begin{abstract}
Adrenocortical carcinoma (ACC) is an aggressive orphan malignancy with less than $35 \%$ 5 -year survival and $75 \%$ recurrence. Surgery remains the primary therapy and mitotane, an adrenolytic, is the only FDA-approved drug with wide-range toxicities and poor tolerability. There are no targeted agents available to date. For the last three decades, H295R cell line and its xenograft were the only available preclinical models. We recently developed two new ACC patient-derived xenograft mouse models and corresponding cell lines (CU-ACC1 and CU-ACC2) to advance research in the field. Here, we have utilized these novel models along with $\mathrm{H} 295 \mathrm{R}$ cells to establish the mitotic PDZ-binding kinase (PBK) as a promising therapeutic target. PBK is overexpressed in ACC samples and correlates with poor survival. We show that PBK is regulated by FOXM1 and targeting PBK via shRNA decreased cell proliferation, clonogenicity and anchorage-independent growth in ACC cell lines. PBK silencing inhibited pAkt, pp38MAPK and pHistone H3 altering the cell cycle. Therapeutically, targeting PBK with the small-molecule inhibitor HITOPK032 phenocopied PBK-specific modulation of pAkt and pHistone H3, but also induced apoptosis via activation of JNK. Consistent with in vitro findings, treatment of CU-ACC1 PDXs with HITOPK032 significantly reduced tumor growth by 5 -fold $(P<0.01)$. Treated tumor tissues demonstrated increased rates of apoptosis and JNK activation, with decreased pAkt and Histone $\mathrm{H} 3$ phosphorylation, consistent with effects observed in ACC cell lines. Together these studies elucidate the mechanism of PBK in ACC tumorigenesis and establish the potential therapeutic potential of HITOPK032 in ACC patients.
\end{abstract}

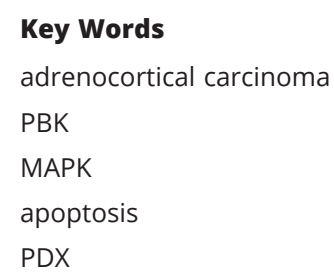

Endocrine-Related Cance (2019) 26, 765-778

\section{Introduction}

Adrenocortical carcinoma (ACC) is an aggressive rare cancer affecting 1-2 persons per-million-per-year with a 5-year survival less than 35\% (Else et al. 2014, Mohan et al. 2018). Surgery is the first-line treatment for localized disease, but therapeutic options are limited for metastatic disease or recurrence (Mohan et al. 2018).
Mitotane, an adrenolytic agent, is the only FDA-approved drug with modest benefits (Hahner \& Fassnacht 2005, Libe 2015, Mohan et al. 2018). Systemic chemotherapy with EDP (etoposide, doxorubicin and cisplatin) is associated with a 5-month progression-free survival (Mohan et al. 2018). The limited effectiveness of currently 
used approaches underscores the need for new therapies for patients with ACC (Berruti et al. 2017, Mohan et al. 2018). Integrated genomic studies have revealed that $60 \%$ of ACC tissues harbor frequent mutations in TP53, ATM and CTNNB1, none of which have been successfully targeted up to date (Else et al. 2014). In addition, 40\% of ACC tumors have no known drivers (Assie et al. 2014, Zheng et al. 2016). IGF2 overexpression has long been considered an important molecular marker of ACC; however, targeting of the IGFR1 receptor yielded disappointing results in clinical trials (Boulle et al. 2001, Barlaskar et al. 2009, Fassnacht et al. 2015, Beuschlein et al. 2016). Previous attempts to target VEGF and EGFR (Quinkler et al. 2008, Chau et al. 2012, Terzolo et al. 2014) have also met with modest success, emphasizing the need for identification and characterization of novel targets in ACC.

Research in the ACC field has been stifled by the lack of preclinical models. In the last three decades, most in vitro and in vivo ACC research has been conducted using a single cell line and its derivative H295R (Wang $\&$ Rainey 2012). We recently developed two new patientderived xenografts (PDXs) ACC and derived cell lines to advance research in this field (Kiseljak-Vassiliades et al. 2018a). Using multiple gene expression microarray data sets comparing ACC, adrenal adenomas and normal adrenal (Kiseljak-Vassiliades et al. 2018b), and consistent with published literature, we observed a dysregulation of cell cycle control genes and its pathway constituents (Kiseljak-Vassiliades et al. 2018b, Mohan et al. 2018). Most prominent was the upregulation of PBK, which has been established as master mitotic kinase known for its role in mitotic division and regulation (Abe et al. 2007, Rizkallah et al. 2015). PBK has been shown to have a critical role in cytokinesis (Matsumoto et al. 2004, Abe et al. 2007, Park et al. 2010, Matsuo et al. 2014, Stauffer et al. 2017) and in cellular proliferation via interaction with p53, modulation of p38MAPK and the DNA damage response (Nandi et al. 2007, Hu et al. 2010, Lei et al. 2013). While PBK is not detectable in most normal human tissues, it is upregulated in several human cancers (He et al. 2010, Brown-Clay et al. 2015, Dou et al. 2015, Chang et al. 2016), where it contributes to a more aggressive phenotype (Park et al. 2006, Brown-Clay et al. 2015, Ohashi et al. 2017). Targeting PBK with the small-molecule inhibitors has been shown to reduce tumor growth or lead to tumor regression in xenograft cancer models (Kim et al. 2012, Matsuo et al. 2014, Joel et al. 2015, Wang et al. 2016).

$P B K$ is 12 -fold increased in ACC tissues compared to normal adrenal samples. In H295R and the recently characterized CU-ACC1 and CU-ACC2 cells, PBK expression was associated with increased tumorigenesis and proliferation. Treatment with the PBK inhibitor, HITOPK032, blocked proliferation and triggered apoptosis in ACC cells, and decreased tumor growth in our newly established in vivo ACC PDX mouse model. Together these findings establish the importance of $\mathrm{PBK}$ as a protumorigenic kinase in ACC and confirm its potential as a therapeutic target for our patients.

\section{Materials and methods}

\section{Analysis of public genomic data sets}

Publically available microarray datasets containing normal adrenal $(n=14)$, adrenal adenoma $(n=22)$ and ACC $(n=77)$ gene expression were analyzed as previously described (Kiseljak-Vassiliades et al. 2018b). Data were analyzed using Partek Genomics Suite 6.6 with the false discovery rate of $<0.05$. With the focus on detecting druggable therapeutic targets, data were screened for differentially regulated kinase transcripts with $>2$-fold differential expression between ACC and normal adrenal samples. Kaplan-Meier, clinical correlation between gene expression and survival outcomes were generated using GraphPad with the TCGA dataset from cBioPortal for Cancer Genomics. RNA expression was normalized using RSEM. Samples with expression Z scores $>2$ were considered dysregulated (Cerami et al. 2012, Gao et al. 2013).

\section{Cell culture}

H295R cells were grown in DMEM/F12 (50:50) media supplemented with 5\% NuSerum, 1\% Antibiotic Pen/Step. CU-ACC1 and CU-ACC2 cells were derived from their respective PDXs and grown in 3:1 (v/v) F-12/DMEM containing $10 \%$ fetal bovine serum and growth factors as previously described (Kiseljak-Vassiliades et al. 2018a,b). All cells were grown at $37^{\circ} \mathrm{C}$ in a $5 \% \mathrm{CO}_{2}$ chamber.

\section{Antibodies and reagents}

The following primary antibodies were used for immunoblot analysis: PARP (\#9542S), pHistone H3 (Ser10) (\#9701S), Histone H3 (\# 4499S), pAkt (Ser473) (\#9271), Akt (\#9272), pERK (p42/44) (9101S), ERK (\#9102), pp38MAPK (\#9211), p38MAPK (\# 9212), pJNK (\#9251S), JNK (\# 9252) from Cell Signaling; FOXM1 (\# SC-500) from Santa Cruz; $\beta$ tubulin (\#ab6046), PBK (\# ab75983) from Abcam. 
For IHC anti-PBK (\#4942S) was purchased from Cell Signaling. The FOXM1 inhibitor, thiostrepton, was obtained from EMD Millipore. PBK inhibitor HITOPK032 was purchased from Sigma.

\section{Plasmids and transduction}

Transfer plasmids were purchased from GE Dharmacon as part of the TRIPZ shRNA starter packaging kit (RHS5087). TRIPZ lentiviral doxycycline-inducible shPBK and shScr plasmids with a TurboRFP fluorescent reporter was bought from Dharmacon (RHS4740) and plasmids were packaged using packaging plasmid mix and transfection reagent in HEK293FT cells using the manufacture's protocol. Cells were transduced at a ratio of $1: 3$ of viral supernatant to media and were selected with $2 \mu \mathrm{g} / \mathrm{mL}$ puromycin for CU-ACC1 and $10 \mu \mathrm{g} / \mathrm{mL}$ for H295R to create stable lines. Doxycycline $2 \mu \mathrm{g} / \mathrm{mL}$ was added to induce shPBK gene expression after stable selection. Cells were sorted for a high RFP signal.

\section{Immunoblot analysis}

Samples were harvested in RIPA buffer, protein was quantified using BCA. Proteins were blotted on PVDF membrane and blocked using 3\% BSA. For most proteins, membranes were incubated overnight with primary antibodies at 1:1000 dilution. Membranes were incubated with p-H3 and p-JNK antibody at 1:500 for 2 days before addition of the secondary antibody. HRP-conjugated rabbit or mouse polyclonal IgG were used as secondary antibodies. Blots were developed using the Thermo Fisher Scientific ECL kit. Densitometry analysis was performed using the NIH ImageJ software. Figures are representative of at least three biological replicates.

\section{Immunohistochemistry}

Immunohistochemistry (IHC) for PBK and pH3 was performed on $5 \mu \mathrm{m}$ thin sections prepared from formalinfixed paraffin-embedded human ACC tumor samples and normal adrenal tissue. Sections were deparaffinized, hydrated, antigen retrieved with standard methods. Incubation with anti-PBK or anti-pH3 was done at 1:50 dilution overnight. Biotinylated anti-rabbit was used as secondary. Slides were developed using $\mathrm{ABC}$ elite Vectastain kit (Vector Laboratories) and DAB staining. Counterstaining was performed with Harris hematoxylin for $1 \mathrm{~min}$. Thereafter, slides were dehydrated following standard protocols and mounted with permount.

\section{Quantitative real-time PCR}

RNA was extracted using RNeasy kit (Qiagen) and reverse transcribed to cDNA (Iscript cDNA synthesis kit; BioRad). The Power SYBR green QPCR master mix from Life Technologies was used for real-time quantitative analysis (Kiseljak-Vassiliades et al. 2018b).

\section{Proliferation, clonogenicity and soft agar assays}

Proliferation assays were performed using the Incucyte ZOOM imaging system from Essen Biosciences (Ann Arbor, MI, USA). Cells were plated at a concentration of 5000 cells/well in a 96-well plate. Standard scans were conducted under $4 \times$ magnification and images were quantified using ImageJ. Clonogenicity and soft assays were carried for 14 days and 21 days respectively, following protocols previously published (KiseljakVassiliades et al. 2018b). Soft agar colonies were stained with Nitroblue tetrazolium salt and colonies were counted from photographed images using an in built macro in ImageJ software (Kar \& Gutierrez-Hartmann 2017).

\section{Double thymidine block and flow cytometry}

ACC cell lines at 50\% confluency were subjected to $2 \mathrm{mM}$ thymidine treatment for $15 \mathrm{~h}$ followed by 9 - $\mathrm{h}$ release followed by an additional $18 \mathrm{~h}$ of $2 \mathrm{mM}$ thymidine treatment. Cells were washed and released in normal media, and cells were either harvested for Western blots in lysis buffer or stained with propidium iodide for flow cytometry analysis. Flow cytometry was performed at CU Cancer Center shared resources and histograms fitted using Modfit.

\section{Caspase $3 / 7$ assays}

Cells were plated in 96-well plate in quadruplicates

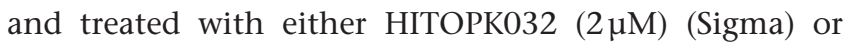
HITOPK032 in combination with SP600125 (10 $\mu \mathrm{M})$ (Selleckchem), a JNK inhibitor. Plates were incubated for $10 \mathrm{~min}$ and luminescence was measured using Promega's protocol for caspase 3/7 glo assay with microplate reader.

\section{Patient-derived xenograft models}

Female athymic nude mice were purchased from Harlan Laboratories (Indianapolis, IN, USA), and PDXs were generated as previously described (Kiseljak-Vassiliades et al. 2018a). Tumors were propagated bilaterally into 
26 mice to obtain 7-9 evaluable tumors per group. When tumors reached $100-400 \mathrm{~mm}^{3}$ mice were randomized into control and HITOPK032-treated groups. Mice received HITOPK032 $10 \mathrm{mg} / \mathrm{kg}$ daily by oral gavage for 17 days and were visually monitored for signs of toxicity. Tumors were measured twice a week by caliper and measurements were recorded in the Study Director Program (San Francisco, CA, USA). Volume was calculated using the formula $\left(\right.$ length $\times$ width $\left.^{2}\right) \times 0.52$. All studies were conducted under animal protocols approved by the University of Colorado Denver Institutional Animal Care and Use Committee.

\section{Statistical analysis}

Data are presented as means \pm S.E.M. from three or more separate experiments. Densitometry analysis performed on immunoblots represent at least three biological replicates. $P$ values were calculated using unpaired Student's $t$-test for two-group comparison or ANOVA (with Bonferroni posttest analysis for multiple comparisons). All data were analyzed and presented using GraphPad Prism software (version 5.0; GraphPad Software).

\section{Results}

\section{PBK is upregulated in ACC and is correlated with poor} survival outcomes in ACC patients

$P B K$ transcript expression was 12-fold upregulated in ACC $(n=77)$ compared to normal adrenals $(n=14)(P<0.001)$ and 7-fold higher compared to adrenal adenomas $(n=22)$ $(P<0.001)$ (Fig. 1A) in the analysis of publicly available microarray gene expression datasets (Kiseljak-Vassiliades et al. 2018b). PBK expression was highly correlated with MK67(Ki 67) (Supplementary Fig. 1, see section on supplementary data given at the end of this article), a major prognostic marker in ACC. Kaplan-Meier estimate of overall survival (OS) in the 75 cases available through cBioPortal (Gao et al. 2013) revealed that high PBK expression in the tumor was associated with significantly poorer overall survival $(\mathrm{OS})(P<0.001)$ with a median OS of 16.1 months (Fig. 1B), and a poorer disease-free survival (DFS) $(P<0.001)$ with a median DFS of 5.31 months in patients with higher PBK transcript levels (Fig. 1C).

Immunoblotting of ACC samples $(n=8$, Fig. 1D) along with H295R, CU-ACC1, CU-ACC2 cell lines and
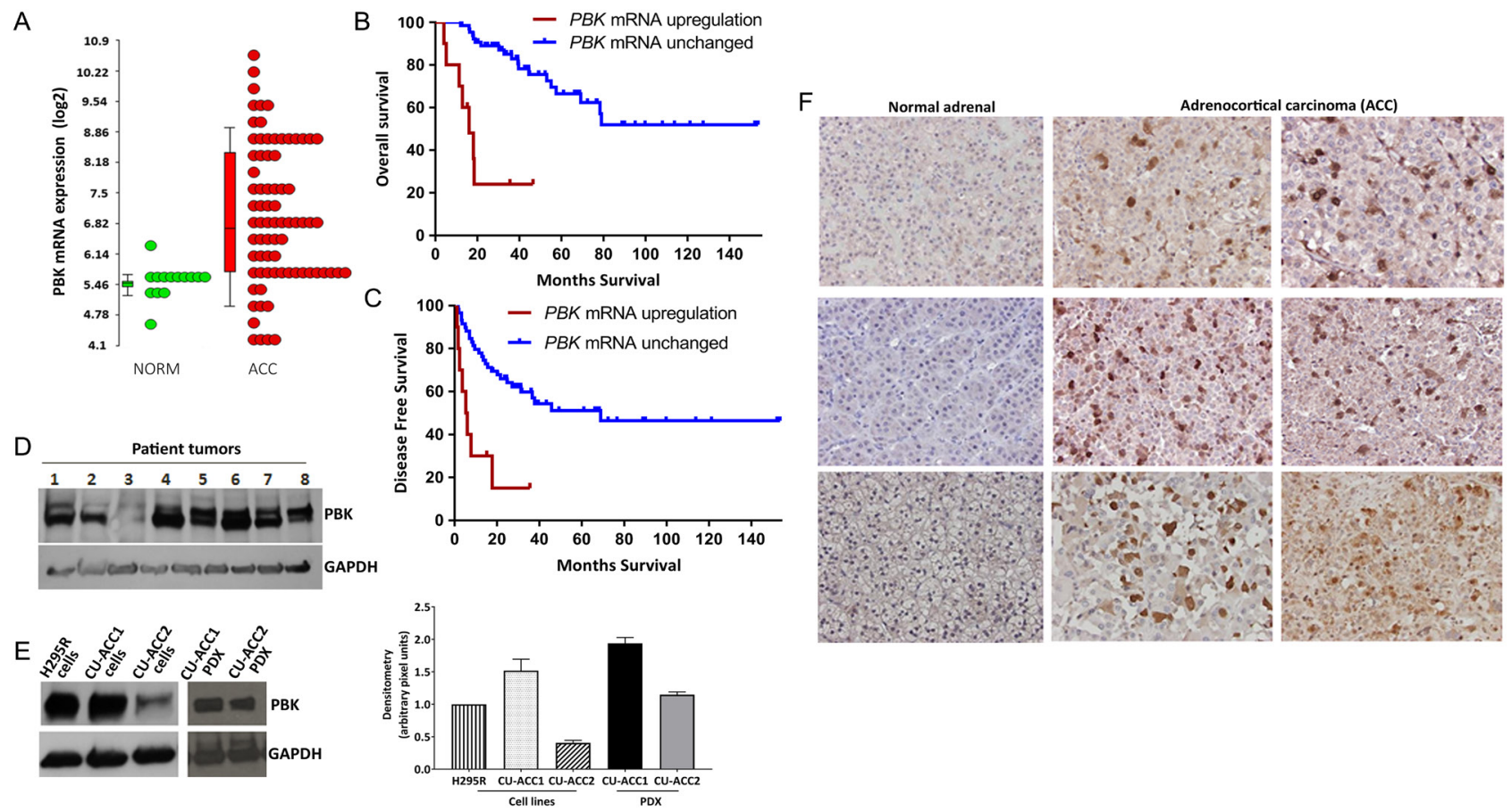

Figure 1

PBK is overexpressed in ACC tumors and dictates survival outcomes. (A) PBK mRNA expression in ACC ( $n=77$ ) is 12-fold higher than normal adrenal tissues $(n=14)$ and 7-fold higher than adenomas $(n=22)$ in microarray gene expression studies. (B and C) Kaplan-Meier analysis of survival using GraphPad Prism with normalized RNA seq data from the TCGA cohort of ACC $(n=75)$ available in cbioportal. RNA expression was normalized using RSEM. $10 \%$ of the population in TCGA cohort had a Z score $>2$ and was designated to have PBK mRNA upregulation. High PBK expression associated with poor OS and poorer disease-free survival (DFS) ( $* * P<0.01)$. (D and E) PBK protein expression in ACC tumor tissues and ACC cell lines and PDXs. Quantification of $\mathrm{E}$ is shown on the right $\mathrm{F}$. IHC with anti-PBK in normal adrenal show no nuclear staining but strong nuclear and diffused cytoplasmic staining in ACC. 
respective PDXs (Fig. 1E) showed high PBK expression in ACC tissues, in H295R and CU-ACC1 cell lines and in the CU-ACC1 and CU-ACC2 PDX. CU-ACC2 cells had 2.5and 4-fold less PBK expression than H295R and CU-ACC1 cells, respectively (Fig. 1E, quantitative graph on right).

Examination of PBK subcellular localization (Fig. 1F) via immunohistochemistry exhibited only low levels of diffuse cytoplasmic PBK staining in normal adrenals, but strong nuclear as well as diffuse cytoplasmic staining in ACC tissues indicating that the nuclear location and higher PBK expression was strictly associated with adrenal carcinogenesis. Together these results further supported the potential oncogenic significance of PBK in ACC.

\section{FOXM1 controls PBK expression in ACC cells}

Prior work has established that FOXM1 regulates several mitotic kinases including MELK (maternal embryonic leucine zipper kinase) and PBK (Kato et al. 2016). Silencing or targeting MELK or PBK in renal cancer cells decreased FOXM1 expression indicating a feedback loop (Kato et al. 2016). In our analysis, the TCGA ACC dataset $(n=75)$ demonstrates a strong $P B K-F O X M 1$ co-expression with a Spearman $r_{\mathrm{s}}=0.903(P<0.001) \quad($ Supplementary Fig. 2A). To examine whether FOXM1 controls PBK expression, H295R, CU-ACC1 and CU-ACC2 cells were treated with the FOXM1 inhibitor, thiostrepton, at doses of $0.5 \mu \mathrm{M}$, $1 \mu \mathrm{M}, 3 \mu \mathrm{M}$ and $5 \mu \mathrm{M}$. FOXM1 and PBK mRNA levels were assessed at $24 \mathrm{~h}$ by qPCR (Supplementary Fig. 2B, C and D). Increasing doses of thiostrepton resulted in a $\sim 1.6$ to 10-fold dose-dependent decrease of FOXM1 expression followed by 2 to 10 -fold decrease in $P B K$ expression $(P<0.05-0.01)$. Immunoblotting showed a similar dosedependent decrease in PBK protein expression with thiostrepton treatment (Supplementary Fig. 2E, F and G), suggesting that FOXM1 is an upstream modulator of PBK in ACC. In contrast to studies in renal carcinoma (Kato et al. 2016), PBK silencing did not decrease FOXM1 protein expression (Supplementary Fig. 2H), suggesting that PBK does not regulate FOXM1 expression in a feedback loop in adrenal cancer.

\section{Silencing PBK inhibits in vitro tumorigenesis in ACC and modulates Akt and MAPK signaling}

Next, the functional role of PBK was examined using two different doxycycline-inducible lentiviral shRNAs (shPBK1 and shPBK3) and a scramble (shScr) control in in vitro models of CU-ACC1, H295R and CU-ACC2 cells. Silencing with either construct was nearly complete in CU-ACC1 cell lines (Fig. 2A insert). In H295R and CU-ACC2 cells, 80 and 30\% silencing was achieved with shPBK1 and shPBK3, respectively (Fig. 2D insert and Supplementary Fig. 3B). Incucyte live cell imaging assay (Fig. 2A) demonstrated that, by day 10, there was on average a 6-fold decrease in proliferation with shPBK1 and shPBK3 in CU-ACC1 cells $(P<0.01)$, whereas a 2.6-fold decrease with shPBK1 and 1.9-fold decrease with shPBK3 $(P<0.01)$ was observed in H295R cell lines compared to controls (Fig. 2D). There was also on average 2.2-fold decrease $(P<0.01)$ in 2 D colony numbers with shPBK1 and shPBK3 in CU-ACC1 cells (Fig. 2B) and an average 6.6-fold decrease $(P<0.01)$ in H295R cells (Fig. 2E). In both cell lines, inhibitory response correlated with the level of PBK silencing achieved. PBK silencing with either constructs also inhibited anchorage-independent growth by 20 -fold in CU-ACC1 cells (Fig. 2C, $P<0.01$ ) and a 4.5 -fold decrease with shPBK1 $(P<0.01)$ and a 2.6 -fold decrease in colony formation with shPBK3 $(P<0.01)$ in H295R cells (Fig. 2F).

The CU-ACC2 cell line, which compared to CU-ACC2 PDX has lower expression of PBK, appeared most resilient to PBK knockdown and showed no significant change in proliferative rates with PBK silencing (Supplementary Fig. 3A). Clonogenicity assays, considered more stringent than proliferative assays, showed a 3.7-fold decrease in colony numbers with shPBK1 $(P<0.01)$ and a 1.7 -fold decrease with shPBK3 $(P<0.05)$ (Supplementary Fig. 3B). Anchorage-independent growth could not be assessed in this model as CU-ACC2 cells failed to form colonies in soft agar.

Since PBK has been implicated in modulation of PI3K and MAPK downstream pathways in other cancers (Ayllon \& O'Connor 2007, Shinde et al. 2013), we next assessed the activation of downstream effectors including pAkt (S473), p38MAPK (Thr180/Tyr182) and pERK (p42/44) in ACC cell lines. PBK silencing resulted on average in a 2-fold decrease in pAkt and 1.8 to 3 fold decrease in p38MAPK $(P<0.05)$ with no effects on ERK activation (Fig. 2G and Supplementary Fig. 3C). Overall, the attenuation in the phosphorylation status correlated with the level of PBK silencing, underscoring PBK-specific effects on downstream signaling in ACC cells.

\section{PBK silencing alters cell cycle progression in CU-ACC1 cell line}

In triple-negative breast cancer, $\mathrm{PBK}$ has been shown to directly phosphorylate Histone $\mathrm{H} 3$ (pH3), consistent with its role as a mitotic kinase (Park et al. 2006). We found that in non-synchronized cells, silencing PBK 

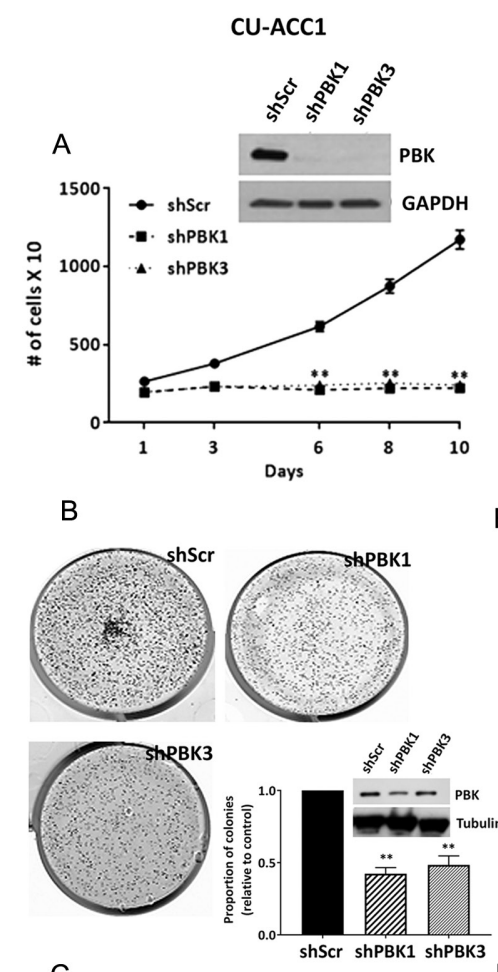

C
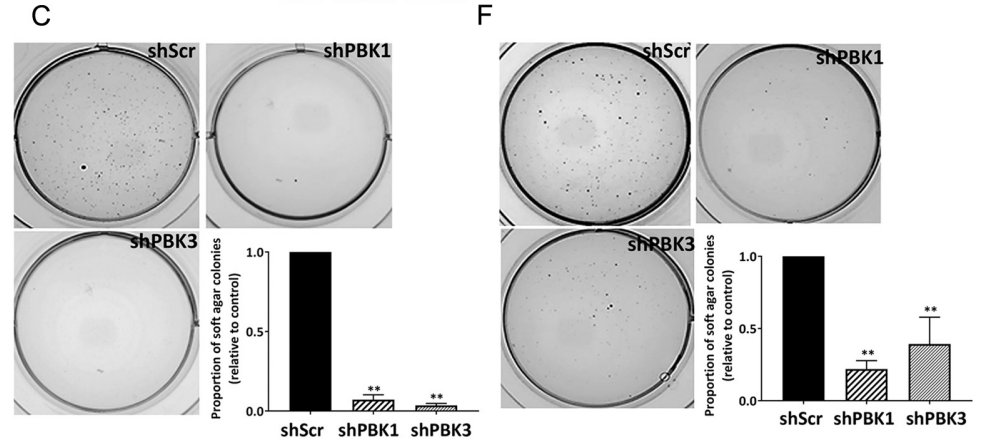

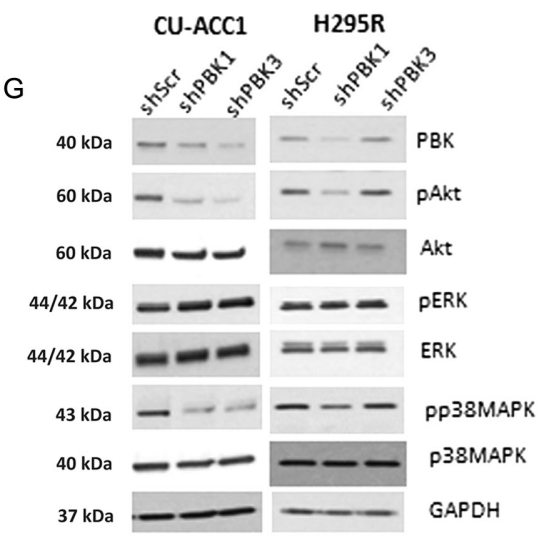

E
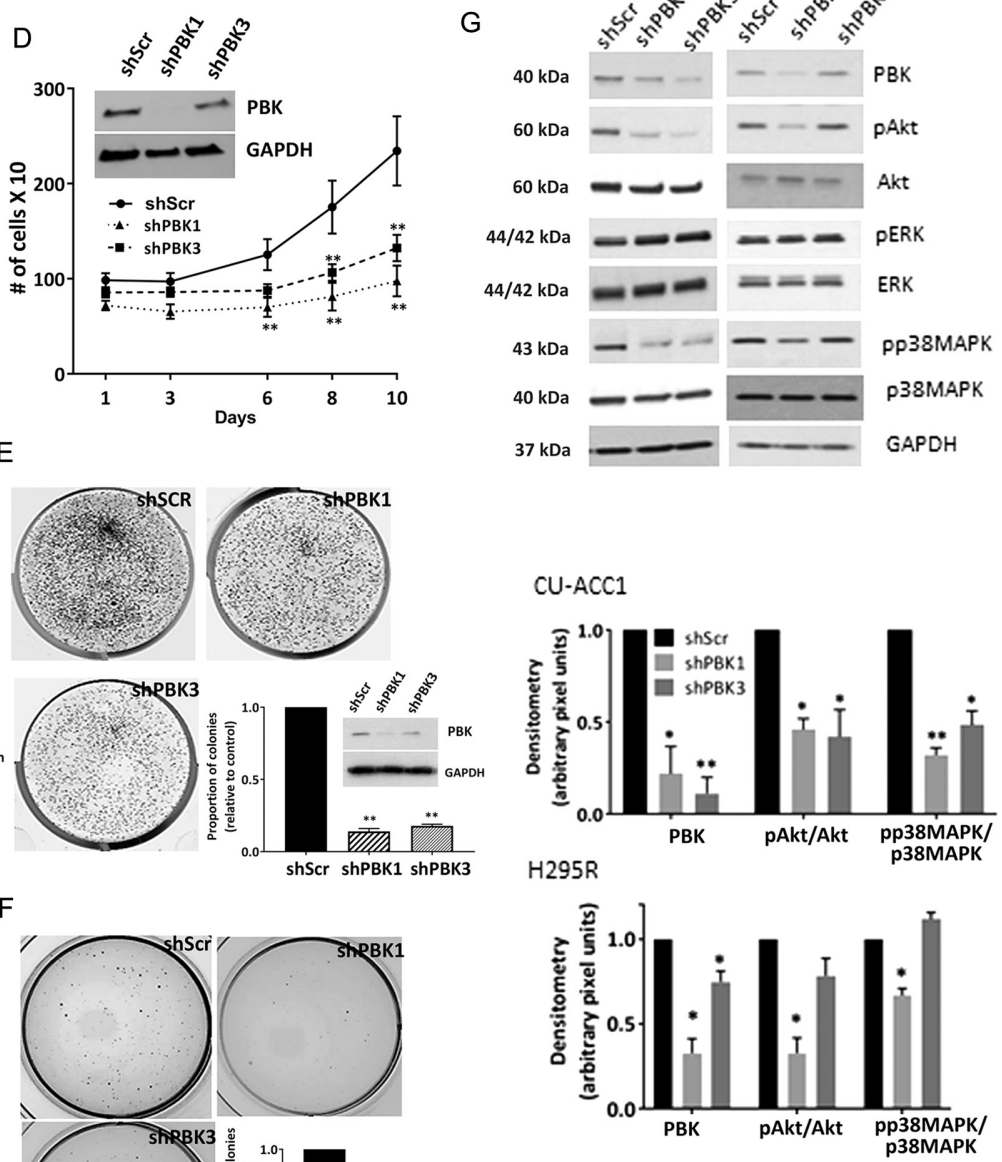

Figure 2

PBK knockdown inhibits cell proliferation, clonogenicity and soft agar colony formation in ACC. (A and D) PBK silencing attenuates proliferation in CU-ACC1 and H295R cell lines. (B and E) PBK knockdown causes on average a 2-fold decrease in colony formation in CU-ACC1 and on average a 6-fold decrease in H295R. (C and F) Knocking down PBK significantly inhibits anchorage-independent growth by 20 -fold in CU-ACC1 and by (4 to 6) fold in H295R cell lines. (G) Immunoblot showing decrease in p-Akt, p-p38MAPK and no change in pERKf with PBK knockdown in CU-ACC1 and H295R cell lines. Data presented have been derived from at least three biological replicates. Data represented as mean \pm S.E.M. ( ${ }^{*} P<0.05$, $* \star P<0.01$ ). Quantification of immunoblots have been done using normalized densitometric values derived at least three biological repeats.

decreased pHistone $\mathrm{H} 3$ on average by 5 -fold in CU-ACC1 $(P<0.01)$, 2-fold in H295R cells $(P<0.05)$ and 1.5 -fold in CU-ACC2 cell lines (Fig. $3 \mathrm{~A}$ and Supplementary Fig. 3C). Upon confirming that ACC cell lines can be synchronized at $\mathrm{G} 1 / \mathrm{S}$ using a double thymidine treatment (Supplementary Fig. 4A), we assessed the effects of PBK silencing on Histone $\mathrm{H} 3$ phosphorylation during cell cycle progression. Examination of pHistone H3 through mitotic progression post block release showed that PBK knockdown completely inhibited induction of pHistone H3 in synchronized CU-ACC1 cell (Supplementary Fig. 4B). The decrease was less prominent in PBK silenced
H295R cells (Supplementary Fig. 4C), which based on $\mathrm{pH} 3$ induction also appeared to maintain the same timeline of mitotic entry and exit as the control cells. Flow cytometry was performed to specifically analyze if PBK silencing affects cell cycle progression in CU-ACC1 cells. Thymidine-blocked scramble control cells showed a 59\% increase in $S$ phase cells over asynchronous cells (Fig. 3B) further confirming effective synchronization at $\mathrm{S}$ phase. Next, percent of cells at different phases of cell cycle was examined in synchronized control and PBK-silenced cells via flow cytometry. Since CU-ACC1 cells did not enter mitosis until $10 \mathrm{~h}$ post thymidine 
A

CU-ACC1

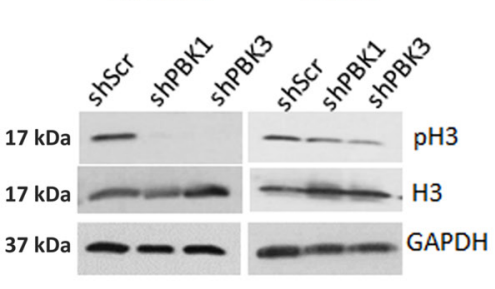

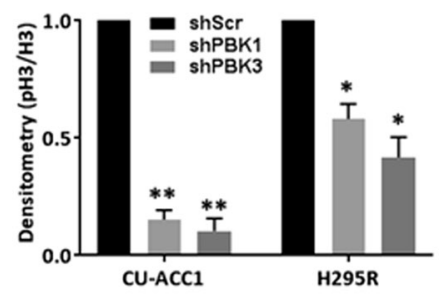

B

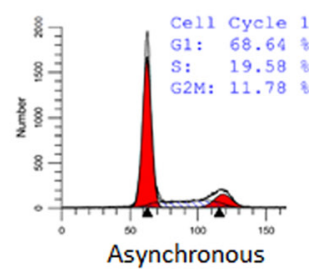

CU-ACC1

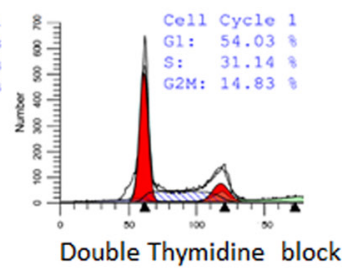

C
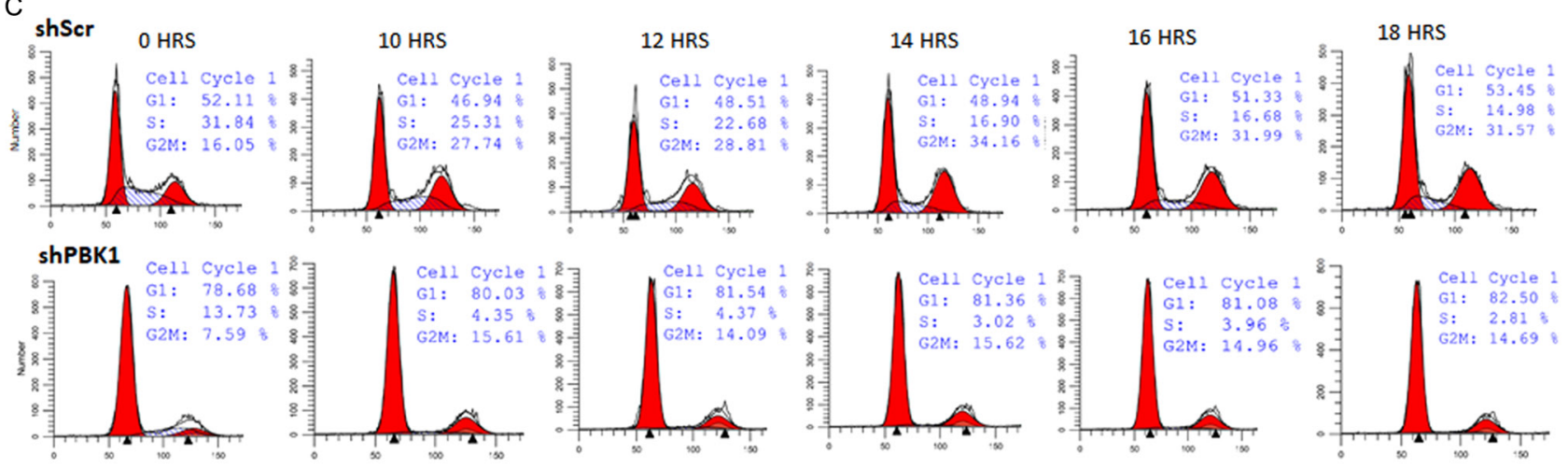

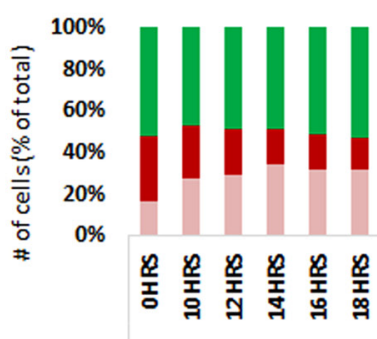

$\square \mathrm{G} 2 / \mathrm{M}=\mathrm{S}=\mathrm{G1}^{\mathrm{shSCr}}$

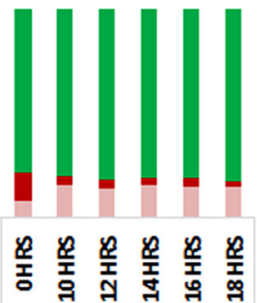

ShPBK1

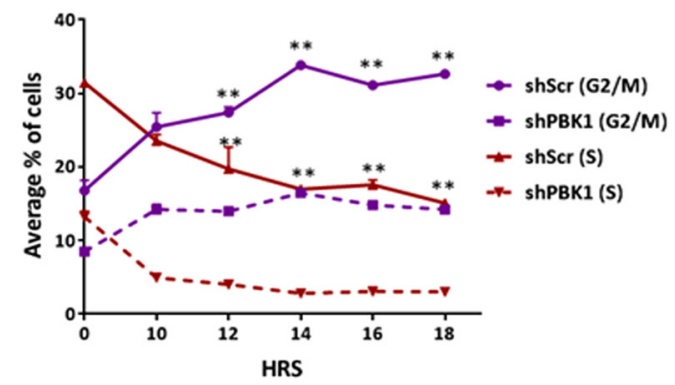

Figure 3

PBK silencing inhibits Histone H3 phosphorylation and alters cell cycle progression. (A) PBK knockdown decreased pHistone H3 in CU-ACC1 and H295R cell lines. Knockdown causes on average a 5 -fold decrease ( $\left.{ }^{*} P<0.01\right)$ in CU-ACC1 and on average 2 -fold decrease $(* P<0.05)$ in H295R as assessed by densitometry. (B) Flow cytometry analysis of asynchronous and double thymidine-blocked CU-ACC1 control shscr cells at $0 \mathrm{~h}$ post release showing a 1.6-fold increase in S phase cells in controls. (C) Cell cycle analysis post thymidine block through $0-18 \mathrm{~h}$, original flow plots and a bar graph visualization of \% cell progression through different time points. (D) Average percent of cells in G2/M and S phase through 0-18 h post release from double thymidine block collected from three experimental replicates. Significant changes in G2/M and S phase cell \% in controls through 12-18 h have been denoted by $\star \star P<0.01$. Data have been derived from three experimental replicates and is represented as mean \pm S.E.M.

block (Supplementary Fig. 4A), cells were collected $10-18 \mathrm{~h}$ post release. Thymidine block release in scramble cells resulted in a decrease in percent $\mathrm{S}$ phase cells and a corresponding increase in $\mathrm{G} 2 / \mathrm{M}$ cells from 10 to $14 \mathrm{~h}$, indicating increasing mitotic entry. By 16 and $18 \mathrm{~h}$, the G2/M cell percent declined, with an increasing G1 percent indicating that cells had begun to slowly exit mitosis and enter G1, all indicative of a regular cell cycle progression (Fig. 3C). In comparison, silencing PBK-blocked cells at G1 as opposed to $\mathrm{S}$ phase observed in controls (Fig. 3C). Following release, however, the percent of cells in G1 did not decline through 10-18 h showing lack of S phase entry. Furthermore compared to $10 \mathrm{~h}, \mathrm{G} 2 / \mathrm{M}$ or $\mathrm{S}$ phase remained unchanged through $12-18 \mathrm{~h}$ indicating a large delay in mitotic entry or exit. We also plotted average G2/M and S phase cell percent from three independent replicates (Fig. 3D). Taken together, these data confirmed that partial silencing of PBK was unable to block cell cycle progression, but altered the duration of cell cycle phases. PBK-silenced cells progressed more slowly through G1 to $\mathrm{S}$ and G2/M causing cells to proliferate slowly compared to controls.

Since prolonged mitosis has been shown to induce apoptosis, we analyzed whether stable PBK knockdown induced apoptosis in ACC tumor cells. No significant change in cleaved PARP or caspase 3 was observed between control and PBK-silenced cells, suggesting that direct modulation of PBK expression has no effect on 
cell apoptotic cell death through PARP and caspase-3 pathways (Supplementary Fig. 5).

\section{Pharmacological inhibition of PBK with HITOPK032 inhibits tumorigenic phenotype in ACC cell lines}

With the future goal of targeting PBK in patients with ACC, we next examined the effects of the available PBK small-molecule inhibitor HITOPK032. The PBK inhibitor, HITOPK032, has been shown to target PBK activity (Kim et al. 2012) at doses less than $40 \mu \mathrm{M}$ (Joel et al. 2015) and suppresses in vitro kinase activity at doses of $2-5 \mu \mathrm{M}$ (Kim et al. 2012). Using proliferation and clonogenicity assays as outcome measures, we tested the long-term cytostatic effects of HITOPK032 at concentrations $\sim 5$ to 25 -fold lower than its reported IC50 (Kim et al. 2012).

As shown in Fig. 4A, B and C, cells were treated with $200 \mathrm{nM}-1 \mu \mathrm{M}$ of HITOPK032 and rates of ACC cell proliferation by live cell imaging were monitored over 8 days. All three ACC cell lines demonstrated dosedependent responses to the PBK inhibitor with significant inhibition in proliferation by day 8 at doses ranging from $600 \mathrm{nM}$ to $1 \mu \mathrm{M}(P<0.01)$. The highest dose tested $(1 \mu \mathrm{M})$ proved to be the most effective dose in inhibiting proliferation at time points as early as day 3 in all cell lines.

Colony forming ability of ACC cells was also impaired with HITOPK032 treatment. Cells were plated at low density and monitored for 14 days (Fig. 4D, E and F), and all were sensitive to HITOPK032 inhibition and exhibited a dose-dependent attenuation of colony formation with doses between 50 and $300 \mathrm{nM}(P<0.01)$. Anchorageindependent growth was not measured as the drug failed to consistently penetrate soft agar layers making data interpretation difficult between experiments.

\section{HITOPK032 treatment decreased Histone H3 phosphorylation, Akt phosphorylation and induced apoptosis via activation of JNK in ACC cells}

Since proliferation assays suggested that at least $1 \mu \mathrm{M}$ of HITOPK032 was required to successfully inhibit proliferation at early time points compared to lower doses with long-term exposure, cells were treated with $0-4 \mu \mathrm{M}$ of HITOPK032 for $24 \mathrm{~h}$ to analyze downstream signaling. At these doses, HITOPK032 did not alter PBK gene expression (Fig. 4G) or the cyclin-dependent kinase 1 (CDK1)-dependent phosphorylation site at Threonine 9 indicating that HITOPK032 does not directly modulate PBK at that specific site (Fig. 4G). HITOPK032 treatment decreased phosphorylation of Akt and histone 3 in all cell lines (Fig. 4G) with no effects on pMEK or its substrate ERK1/2. Multiple experimental replicates revealed that the decrease in Akt activation was most significant at $4 \mu \mathrm{M}$ and ranged from 1.4 to 1.8 -fold across ACC cell lines $(P<0.05)$. A dose-dependent decrease in pHistone H3 was observed at 2 and $4 \mu \mathrm{M}$. CU-ACC1 and H295R cells appeared more sensitive to HITOPK032 than CU-ACC2 with both cell lines exhibiting a 3 -fold average decrease in histone 3 phosphorylation $(P<0.05)$ (Fig. 4G).

To determine if HITOPK032 affected cellular survival, apoptosis in HITOPK032 treated cell lines was measured at 24 and $48 \mathrm{~h}$ assessing cleaved caspase- 3 and PARP as markers of cell death (Fig. 5A). Concentrations of HITOPK032 of $1 \mu \mathrm{M}$ and higher elicited a dose-dependent apoptotic response at $48 \mathrm{~h}$ in all cell lines $(P<0.05)$. CU-ACC1 cells were more sensitive to HITOPK032 treatment with increased PARP and caspase- 3 cleavages at a dose of $1 \mu \mathrm{M}$ as early as $24 \mathrm{~h}(P<0.01)$. The highest dose of HITOPK032 $(4 \mu \mathrm{M})$ induced apoptosis in all cell lines at $24 \mathrm{~h}(P<0.01)$.

In nasopharyngeal carcinoma, HITOPK032 has been implicated in stress induction via activation of JNK (Wang et al. 2016). We observed similar activation of JNK/SAPK in CU-ACC1 and H295R cell lines treated with HITOPK032 at doses from 0 to $4 \mu \mathrm{M}$. CU-ACC2 cells did not show any significant JNK activation (Fig. 5B). To investigate if pJNK contributed to HITOPK032 mediated apoptosis, we pretreated CU-ACC1 and H295R cells with SP600125 (10 $\mathrm{MM})$, the pJNK inhibitor, overnight. Cells were then incubated with $4 \mu \mathrm{M}$ HITOPK032 in the absence or presence of specific signaling pathway inhibitors for $24 \mathrm{~h}$ before caspase activation was measured (Fig. 5C). Treatment with HITOPK032 induced a 2-fold increase in caspase activation in CU-ACC1 and H295R cells compared to controls (Fig. 5C). Combination treatment with the JNK inhibitor SP600125 $(10 \mu \mathrm{M})$ with HITOPK032 $(4 \mu \mathrm{M})$ resulted in 1.2-fold decrease in caspase activation in CU-ACC1 and a 1.5-fold reduction in H295R cell lines compared to only HITOPK032 $(4 \mu \mathrm{M})$ treated cells, suggesting that induction of apoptosis in ACC cell lines in response to HITOPK032 treatment is in part through JNK activation.

\section{Targeting of PBK inhibits tumor growth in CU-ACC1 PDX model in athymic nude mice}

We next pharmacologically targeted PBK in ACC PDX tumor models in athymic nude mice (Kiseljak-Vassiliades et al. 2018a). CU-ACC1 PDX animals were randomized into control and HITOPK032 treatment groups with 

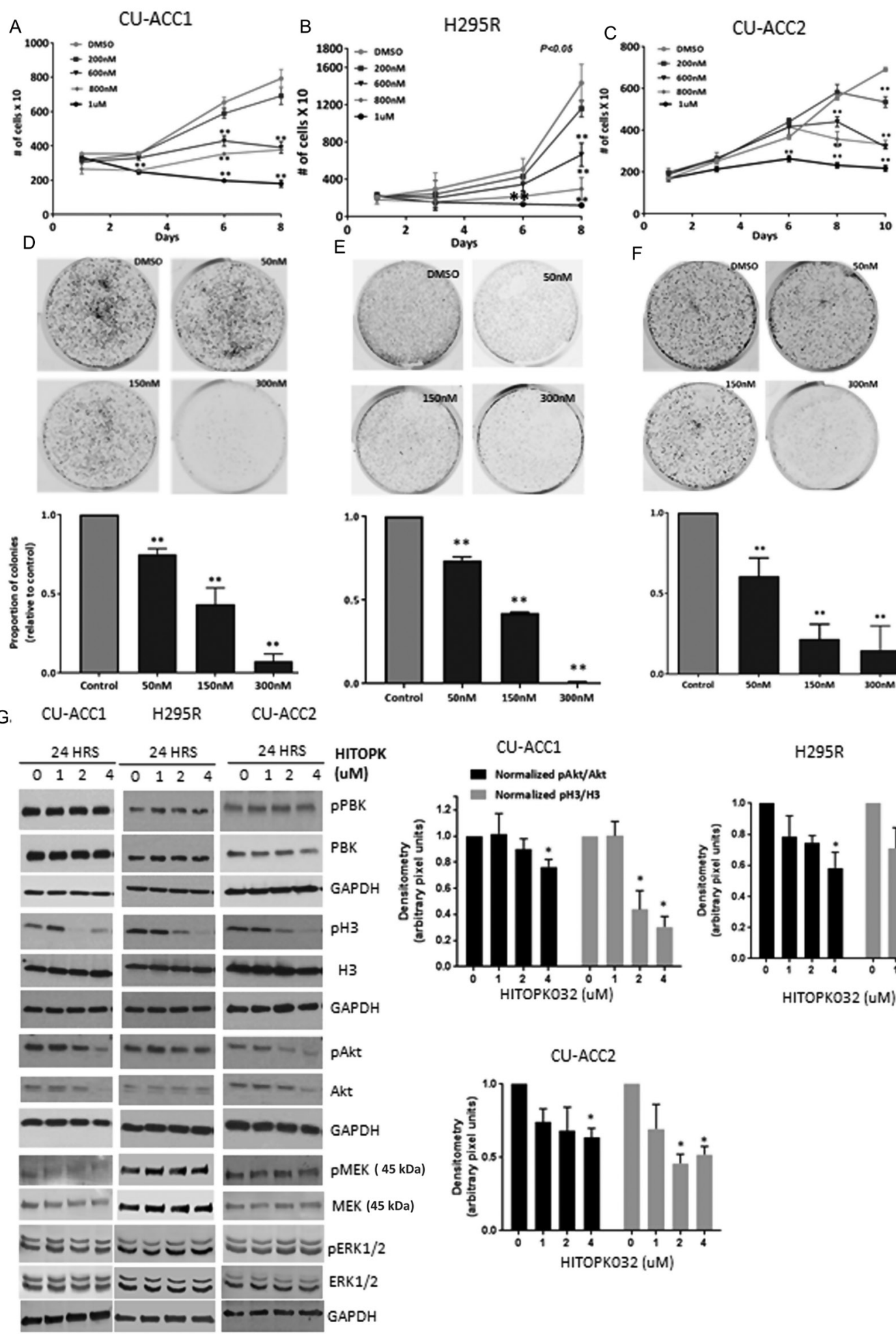

CU-ACC1

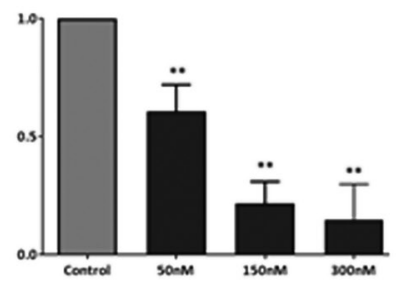

- Normalized pakt/Akt

$\mathrm{H} 295 \mathrm{R}$
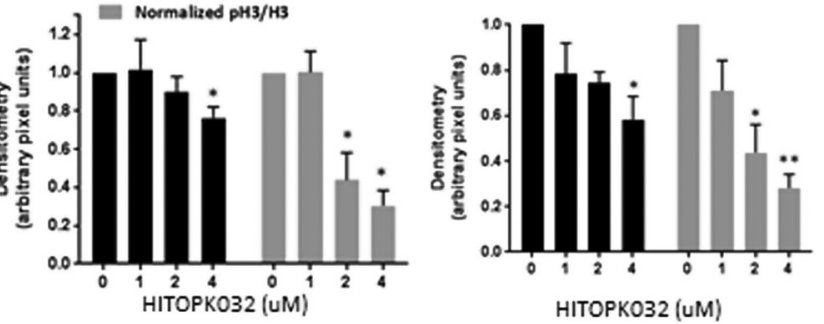

CU-ACC2

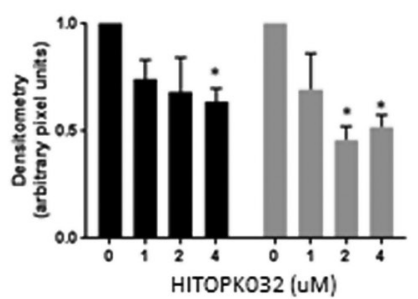

Figure 4

HITOPK032 treatment inhibits tumorigenic properties and recapitulates effects of PBK silencing in ACC. (A, B and C) Cell lines show a dose-dependent response to HITOPK032 treatment at $600-1 \mu \mathrm{M}$ range ( $* * P<0.01$ ) by day 8 . Graphs shown are representative experiments of three biological repeats; data presented as mean \pm S.E.M. (D, E and F) Dose-dependent decrease in colony formation to doses of 50-300 nM of HITOPK032. (G) HITOPK032 decreases Akt and Histone $\mathrm{H} 3$ phosphorylation as shown via immunobloting. $P$ values ( $* * P 0.01, * P<0.05$ ) have been calculated using normalized densitometric values derived from immunoblots of at least three biological repeats. All normalization has been done to the DMSO control. Data represented as mean \pm S.E.M. 


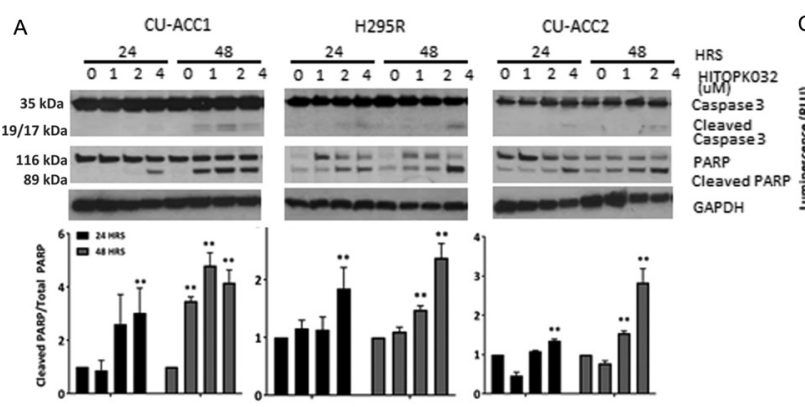

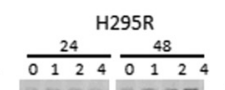

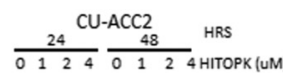

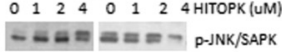

$=\Sigma=-\Xi \Sigma=-\mathrm{JNK} / \mathrm{SAPK}$

DED -OSAPDH

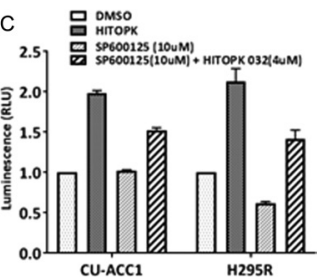

CU-ACC1
Figure 5

Apoptosis induced by HITOPK032 is in part mediated by JNK activation. (A) HITOPK032 at $1 \mu \mathrm{M}$ or higher induces apoptosis in a dose dependent manner by $48 \mathrm{~h}$ in all cell lines. (B) HITOPK treatment induces JNK phosphorylation in CU-ACC1 and H295R cell lines. (C) Treating CU-ACC1 and H295R cell lines with $10 \mu \mathrm{M}$ of the JNK inhibitor in presence of $4 \mu \mathrm{M}$ HITOPK032 partially inhibits caspase $3 / 7$ activity measured by the caspase $3 / 7$ glo assay. $P$ values $(* * P<0.01, * P<0.05)$ have been calculated from normalized RLU of at least three biological repeats. Quantification of immunoblots have been derived from normalized densitometric values from three independent replicates. All normalization has been done to the DMSO control. Data represented as mean \pm S.E.M. average tumor size of $198 \mathrm{~cm}^{3}$ in control group and $139 \mathrm{~cm}^{3}$ in the treatment group $(P=0.13)$. At the initiation of the study there were 7 trackable tumors in the control and 11 in the treated groups, but three mice in the treatment group had to be killed early because of skin bruising resulting in eight HITOPK032-treated tumors at the completion of the study. Mice were dosed at
$10 \mathrm{mg} / \mathrm{kg}$ once daily by oral gavage for 17 days. Figure $6 \mathrm{~A}$ shows significant decreases in the rate of tumor growth by day 14 and 17 in the HITOPK032 group compared to controls $(P<0.01)$ with representative images of tumors harvested at the completion of the study (Fig. 6B). There was wide variability in the rates of tumor growth in the control group; therefore, changes in individual tumor
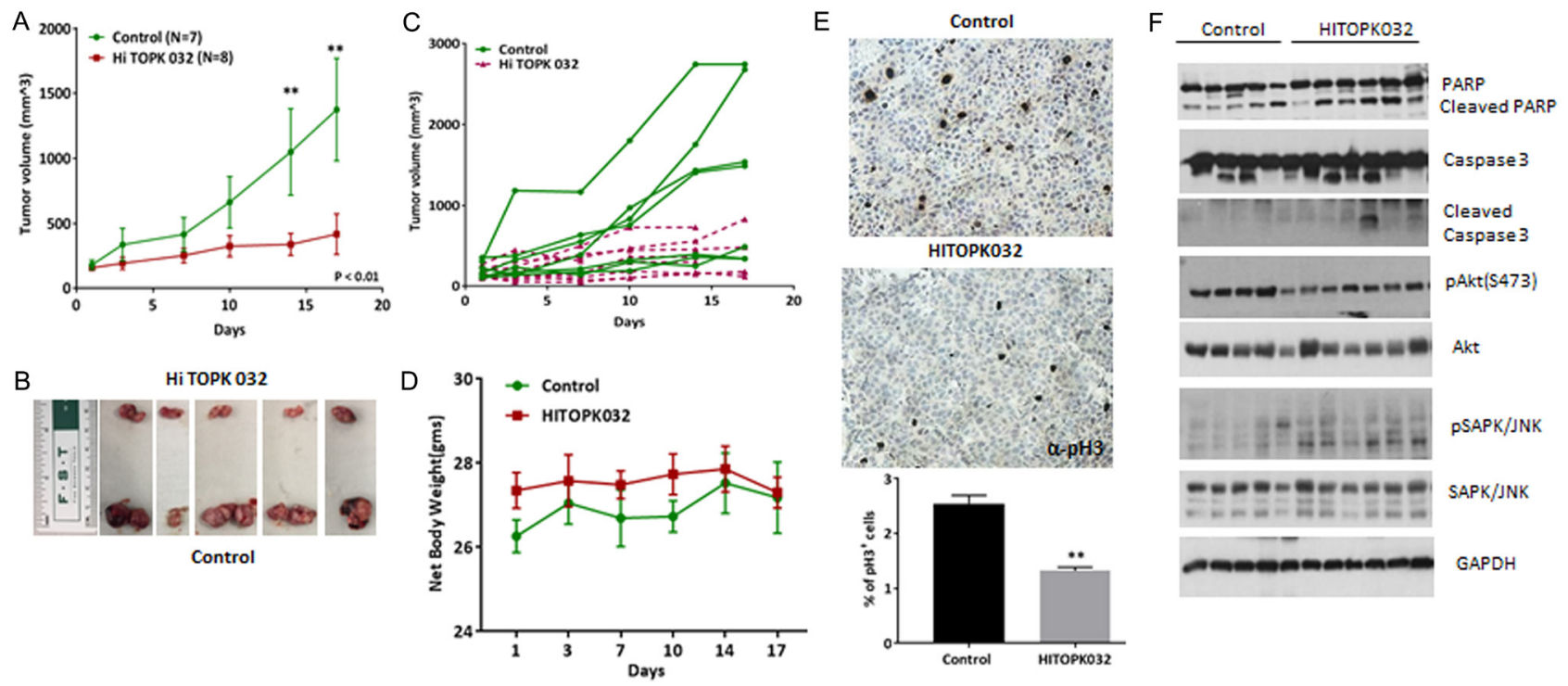

Figure 6

HITOPK032 inhibits tumorigenic growth in ACC. (A) HITOPK032 treatment in athymic nude mice bearing passage 14 CU-ACC1 PDXs shows significant decrease in tumor rate by day 14 and day $17(* * P<0.01)$. (B) A representative image of tumors harvested at the end of the study. Treated group has smaller tumor size compared to control. (C) Graph showing growth rates of individual tumors following HITOPK032 treatment. (D) Average net weight of mice in treated and the control group shows no significant change in body weight. (E) IHC analysis of pHistone $\mathrm{H} 3$ in tissue sections of control and treated tumors. There is 1.9 -fold decrease in histone 3 phosphorylation in treated group relative to control ( $* * P<0.01)$. (F) Immunoblot of representative tumor lysates from five control and six treated tumors collected from individual mice showing difference in cleaved PARP, cleaved caspase 3, pAkt and pJNK expression between control and treated group $(* P<0.05, * * P<0.01)$. 
volume through the length of the study are also depicted to show individual tumor response (Fig. 6C). Body weight of the mice was used as an indicator of toxicity and no significant difference between the treated and the control group was observed (Fig. 6D).

Representative tumor tissue from each mouse in the control and treated group was analyzed for pHistone H3, and PARP and caspase- 3 cleavage to assess apoptosis. HITOPK032-treated tissues $(n=8)$ showed a 1.9-fold decrease in pHistone $\mathrm{H} 3$ compared to controls $(n=7)$ as measured by immunohistochemistry (Fig. 6E). Cleaved PARP and caspase- 3 was higher in six out of seven treated tumors compared to one out of five tumors in the control group, suggesting that HITOPK032 treatment induced an apoptotic response in ACC PDX tumors (Fig. 6F). There was also an increase in pJNK and a decrease in pAkt expression in the treated tissues compared to controls (Fig. 6F). Taken together, these results confirm that the in vivo effects recapitulated the in vitro effects of HITOPK032 treatment to inhibit ACC tumorigenesis.

\section{Discussion}

ACC is an understudied cancer largely unresponsive to currently available systemic treatments (Armignacco et al. 2018). In this study, we have identified the mitotic kinase, $\mathrm{PBK}$, as a highly expressed and a putative therapeutic target in ACC. In contrast to normal tissues, PBK is overexpressed in various cancers and is a predictor of adverse clinical outcomes (Luo et al. 2014, Chang et al. 2016, Kwon et al. 2016, Ohashi et al. 2016), but only a handful of studies have examined the mechanistic role of PBK in tumorigenesis.

Here, we have provided supporting evidence for PBK's role in ACC tumorigenesis using cell lines derived from human ACC tumors with different genetic background (Kiseljak-Vassiliades et al. 2018a) and with varied level of PBK expression. Overall, our studies demonstrate that ACC cell lines such as H295R and CU-ACC1, which have higher level of PBK expression are reliant on the mitotic kinase to drive their growth phenotype, although their background heterogeneity dictates the extent to which PBK-dependent downstream effectors modulate various pro-proliferative and pro-tumorigenic pathways. Phosphorylation p38MAPK and of Histone H3, which have been shown to be direct targets of PBK appeared to be key common effectors of PBK-mediated growth (Fig. 4G) in all cell lines. For an indirect target such as Akt, PBK silencing decreased Akt activation in CU-ACC1 and H295R cells but not in CU-ACC2 cell lines. CU-ACC2, which also had the lowest level of PBK expression, also appeared resistant to PBK silencing as observed in the proliferative assays.

In breast cancer, PBK silencing inhibited pHistone H3 and led to dysfunction of cytokinesis promoting apoptosis (Park et al. 2006). We showed that PBK knockdown did not induce apoptosis in ACC cell lines. In the prototype CU-ACC1 cells, PBK knockdown caused a greatly delayed G2/M phase and, the initial G1 accumulation upon thymidine treatment. This was in contrast to an $\mathrm{S}$ phase accumulation observed in the control cells with the double thymidine block. Moreover, the initial G1 accumulation increased through $18 \mathrm{~h}$ post release suggesting that PBK silencing in CU-ACC1 allowed more cells to accumulate at G1 at any given time. This observation was also in agreement with the severe growth restricted phenotype observed upon PBK knockdown in CU-ACC1 cell lines. Hence, rather than triggering apoptosis, PBK silencing restricted the ability of the cell lines, especially CU-ACC1, to proliferate as evidenced by the growth curves shown in Fig. 2A. H295R cells, which have a non-functional p53 (Sampaoli et al. 2012) and activated beta catenin, appeared to be resilient to cell cycle alteration with PBK knockdown and also exhibited less alterations in rates of proliferation than CU-ACC1.

To examine whether PBK can be effectively targeted via a small-molecule inhibitor, we used HITOPK032, a putative PBK inhibitor (Kim et al. 2012). HITOPK032 recapitulated shPBK-specific effects by inhibiting pHistone $\mathrm{H} 3$ and pAkt in H295R, CU-ACC1 and CU-ACC2 cell lines, but in addition, induced apoptosis via activation of JNK. These data suggest that HITOPK032 acts via PBK-independent stress pathways. Prior studies have defined a role of PBK in the DNA damage response (Ayllon \& O'Connor 2007). Although further studies are required to determine causes behind JNK activation, we hypothesize that a component of the HITOPK032-mediated effects may be dependent on a DNA damage response in ACC tumors. Another possibility is that similar to nasopharyngeal carcinoma, HITOPK032 treatment of ACC induced reactive oxygen species and ER stress (Wang et al. 2016).

Examining the efficacy of therapeutic targeting in in vivo models which closely recapitulate human tumors (Tentler et al. 2012) has been a long unmet need in the field of ACC. We showed that HITOPK032 effectively inhibited tumor growth using the first PDX model in the field of adult ACC. PDXs have been shown to have minimal drift (Tentler et al. 2012) from the matching tumor in early passages and represent human tumorigenesis with 
respect to tumor architecture, gene signature, stroma and mutational signature. Treatment responses in PDX are more reflective of the clinical drug's effectiveness than xenograft in vivo studies (Tentler et al. 2012). We have also validated downstream effectors of HITOPK032 in the harvested PDX tumor tissues demonstrating that the in vivo responses closely recapitulated effects of in vitro experiments, which is encouraging for future target development.

In summary, we have shown that targeting PBK, both genomically and pharmacologically, inhibits tumorigenic growth in preclinical models of ACC. Our data suggest that targeting with HITOPK032 may be more effective than PBK silencing alone since HITOPK032 induces additional PBK-independent cell death, the mechanism of which requires additional investigation. Moreover, our data provide early indications that HITOPK032 is able to trigger stress response pathways. Mitotane, an adrenolytic drug used to treat patients with ACC has been shown to cause ER stress (Sbiera et al. 2015). Studies with H295R cells have shown that mitotane at low concentrations can be paired with other chemotherapeutic drugs to synergistically antagonize tumor growth (De Martino et al. 2016). Future investigations will test in our new preclinical models the hypothesis that disruption of specific components of the cell the cycle such as PBK in conjunction with mitotane, a known ER stress inducer, will enhance the anti-tumorigenic responses in ACC and provide new treatment strategies for our patients with ACC.

\section{Supplementary data}

This is linked to the online version of the paper at https://doi.org/10.1530/ ERC-19-0292.

\section{Declaration of interest}

The authors declare that there is no conflict of interest that could be perceived as prejudicing the impartiality of the research reported.

\section{Funding}

This work was supported by NIH K12CA086913-12 (to K K V), NIH K08CA222620 (to K K V), Cancer League of Colorado Award (to K K V and $\mathrm{S}$ L), Doris Duke CU-FSRC (to K K V), Veterans Affairs Merit Review Award 001 (to M E W), University of Colorado Cancer Center Support Grant P30CA046934. The funding bodies had no role in the design of the study and collection, analysis and interpretation of data or in writing the manuscript.

\section{Author contribution statement}

Conception and design: A Kar, K Kiseljak-Vassiliades, M E Wierman. Development of methodology: A Kar, Y Zhang. Acquisition of data: A Kar,
Y Zhang, J Saeed, S Bagby, B Yacob. Analysis and interpretation of data: A Kar, K Kiseljak-Vassiliades. Writing, review and/or revision of manuscript: A Kar, K Kiseljak-Vassiliades, M E Wierman. Administrative, technical or material support: T Pitts, S Leong, K Kiseljak-Vassiliades, H Somerset, M E Wierman. Study supervision: K Kiseljak-Vassiliades, M E Wierman.

\section{Acknowledgements}

The authors thank the University of Colorado (UCD) Laboratory Animal Resources, Protein production/MoAb/Tissue culture core, flow cytometry shared resource facility (FCSR), genomics and genomics and miroarray core for providing space and services for acquisition of data. The authors thank Dr Lauren Fishbein (Endocrinology, UCD) for reviewing the manuscript.

\section{References}

Abe Y, Takeuchi T, Kagawa-Miki L, Ueda N, Shigemoto K, Yasukawa M \& Kito K 2007 A mitotic kinase TOPK enhances Cdk1/cyclin B1-dependent phosphorylation of PRC1 and promotes cytokinesis. Journal of Molecular Biology 370 231-245. (https://doi.org/10.1016/j. jmb.2007.04.067)

Armignacco R, Cantini G, Canu L, Poli G, Ercolino T, Mannelli M \& Luconi M 2018 Adrenocortical carcinoma: the dawn of a new era of genomic and molecular biology analysis. Journal of Endocrinological Investigation 41 499-507. (https://doi.org/10.1007/s40618-0170775-y)

Assie G, Letouze E, Fassnacht M, Jouinot A, Luscap W, Barreau O, Omeiri H, Rodriguez S, Perlemoine K, Rene-Corail F, et al. 2014 Integrated genomic characterization of adrenocortical carcinoma. Nature Genetics 46 607-612. (https://doi.org/10.1038/ng.2953)

Ayllon V \& O'Connor R 2007 PBK/TOPK promotes tumour cell proliferation through p38 MAPK activity and regulation of the DNA damage response. Oncogene 26 3451-3461. (https://doi.org/10.1038/ sj.onc.1210142)

Barlaskar FM, Spalding AC, Heaton JH, Kuick R, Kim AC, Thomas DG, Giordano TJ, Ben-Josef E \& Hammer GD 2009 Preclinical targeting of the type I insulin-like growth factor receptor in adrenocortical carcinoma. Journal of Clinical Endocrinology and Metabolism 94 204-212. (https://doi.org/10.1210/jc.2008-1456)

Berruti A, Grisanti S, Pulzer A, Claps M, Daffara F, Loli P, Mannelli M, Boscaro M, Arvat E, Tiberio G, et al. 2017 Long-term outcomes of adjuvant mitotane therapy in patients with radically resected adrenocortical carcinoma. Journal of Clinical Endocrinology and Metabolism 102 1358-1365. (https://doi.org/10.1210/jc.2016-2894)

Beuschlein F, Jakoby J, Mentz S, Zambetti G, Jung S, Reincke M, Suss R \& Hantel C 2016 IGF1-R inhibition and liposomal doxorubicin: progress in preclinical evaluation for the treatment of adrenocortical carcinoma. Molecular and Cellular Endocrinology 428 82-88. (https:// doi.org/10.1016/j.mce.2016.03.023)

Boulle N, Baudin E, Gicquel C, Logie A, Bertherat J, Penfornis A, Bertagna X, Luton JP, Schlumberger M \& Le Bouc Y 2001 Evaluation of plasma insulin-like growth factor binding protein-2 as a marker for adrenocortical tumors. European Journal of Endocrinology 144 29-36. (https://doi.org/10.1530/eje.0.1440029)

Brown-Clay JD, Shenoy DN, Timofeeva O, Kallakury BV, Nandi AK \& Banerjee PP 2015 PBK/TOPK enhances aggressive phenotype in prostate cancer via beta-catenin-TCF/LEF-mediated matrix metalloproteinases production and invasion. Oncotarget 6 15594-15609. (https://doi.org/10.18632/oncotarget.3709)

Cerami E, Gao J, Dogrusoz U, Gross BE, Sumer SO, Aksoy BA, Jacobsen A, Byrne CJ, Heuer ML, Larsson E, et al. 2012 The cBio cancer genomics portal: an open platform for exploring multidimensional cancer genomics data. Cancer Discovery 2 401-404. (https://doi.org/10.1158/2159-8290.CD-12-0095)
(C) 2019 Society for Endocrinology Published by Bioscientifica Ltd. Printed in Great Britain 
Chang CF, Chen SL, Sung WW, Hsieh MJ, Hsu HT, Chen LH, Chen MK, Ko JL, Chen CJ \& Chou MC 2016 PBK/TOPK expression predicts prognosis in oral cancer. International Journal of Molecular Sciences $\mathbf{1 7}$ 1007. (https://doi.org/10.3390/ijms17071007)

Chau NG, Hotte SJ, Chen EX, Chin SF, Turner S, Wang L \& Siu LL 2012 A phase II study of sunitinib in recurrent and/or metastatic adenoid cystic carcinoma (ACC) of the salivary glands: current progress and challenges in evaluating molecularly targeted agents in ACC. Annals of Oncology 23 1562-1570. (https://doi.org/10.1093/annonc/mdr522)

De Martino MC, van Koetsveld PM, Feelders RA, Lamberts SW, de Herder WW, Colao A, Pivonello R \& Hofland LJ 2016 Effects of combination treatment with sirolimus and mitotane on growth of human adrenocortical carcinoma cells. Endocrine 52 664-667. (https://doi.org/10.1007/s12020-015-0818-0)

Dou X, Wei J, Sun A, Shao G, Childress C, Yang W \& Lin Q 2015 PBK/ TOPK mediates geranylgeranylation signaling for breast cancer cell proliferation. Cancer Cell International 15 27. (https://doi. org/10.1186/s12935-015-0178-0)

Else T, Kim AC, Sabolch A, Raymond VM, Kandathil A, Caoili EM, Jolly S, Miller BS, Giordano TJ \& Hammer GD 2014 Adrenocortical carcinoma. Endocrine Reviews 35 282-326. (https://doi.org/10.1210/ er.2013-1029)

Fassnacht M, Berruti A, Baudin E, Demeure MJ, Gilbert J, Haak H, Kroiss M, Quinn DI, Hesseltine E, Ronchi CL, et al. 2015 Linsitinib (OSI-906) versus placebo for patients with locally advanced or metastatic adrenocortical carcinoma: a double-blind, randomised, phase 3 study. Lancet: Oncology 16 426-435. (https://doi.org/10.1016/ S1470-2045(15)70081-1)

Gao J, Aksoy BA, Dogrusoz U, Dresdner G, Gross B, Sumer SO, Sun Y, Jacobsen A, Sinha R, Larsson E, et al. 2013 Integrative analysis of complex cancer genomics and clinical profiles using the cBioPortal. Science Signaling 6 pl1. (https://doi.org/10.1126/scisignal.2004088)

Hahner S \& Fassnacht M 2005 Mitotane for adrenocortical carcinoma treatment. Current Opinion in Investigational Drugs 6 386-394.

He F, Yan Q, Fan L, Liu Y, Cui J, Wang J, Wang L, Wang Y, Wang Z, Guo Y, et al. 2010 PBK/TOPK in the differential diagnosis of cholangiocarcinoma from hepatocellular carcinoma and its involvement in prognosis of human cholangiocarcinoma. Human Pathology 41 415-424. (https://doi.org/10.1016/j. humpath.2009.05.016)

Hu F, Gartenhaus RB, Eichberg D, Liu Z, Fang HB \& Rapoport AP 2010 PBK/TOPK interacts with the DBD domain of tumor suppressor p53 and modulates expression of transcriptional targets including p21. Oncogene 29 5464-5474. (https://doi.org/10.1038/onc.2010.275)

Joel M, Mughal AA, Grieg Z, Murrell W, Palmero S, Mikkelsen B, Fjerdingstad HB, Sandberg CJ, Behnan J, Glover JC, et al. 2015 Targeting PBK/TOPK decreases growth and survival of glioma initiating cells in vitro and attenuates tumor growth in vivo. Molecular Cancer 14 121. (https://doi.org/10.1186/s12943-0150398-x)

Kar A \& Gutierrez-Hartmann A 2017 ESE-1/ELF3 mRNA expression associates with poor survival outcomes in HER2(+) breast cancer patients and is critical for tumorigenesis in HER2(+) breast cancer cells. Oncotarget 8 69622-69640. (https://doi.org/10.18632/ oncotarget.18710)

Kato T, Inoue H, Imoto S, Tamada Y, Miyamoto T, Matsuo $\mathrm{Y}$, Nakamura Y \& Park JH 2016 Oncogenic roles of TOPK and MELK, and effective growth suppression by small molecular inhibitors in kidney cancer cells. Oncotarget 7 17652-17664. (https://doi. org/10.18632/oncotarget.7755)

Kim DJ, Li Y, Reddy K, Lee MH, Kim MO, Cho YY, Lee SY, Kim JE, Bode AM \& Dong Z 2012 Novel TOPK inhibitor HI-TOPK-032 effectively suppresses colon cancer growth. Cancer Research $\mathbf{7 2}$ 3060-3068. (https://doi.org/10.1158/0008-5472.CAN-11-3851)

Kiseljak-Vassiliades K, Zhang Y, Bagby SM, Kar A, Pozdeyev N, Xu M, Gowan K, Sharma V, Raeburn CD, Albuja-Cruz M, et al. 2018a
Development of new preclinical models to advance adrenocortical carcinoma research. Endocrine-Related Cancer 25 437-451. (https:// doi.org/10.1530/ERC-17-0447)

Kiseljak-Vassiliades K, Zhang Y, Kar A, Razzaghi R, Xu M, Gowan K, Raeburn CD, Albuja-Cruz M, Jones KL, Somerset H, et al. 2018b Elucidating the role of the maternal embryonic leucine zipper kinase (MELK) in adrenocortical carcinoma. Endocrinology 159 2532-2544. (https://doi.org/10.1210/en.2018-00310)

Kwon CH, Park HJ, Choi YR, Kim A, Kim HW, Choi JH, Hwang CS, Lee SJ, Choi CI, Jeon TY, et al. 2016 PSMB8 and PBK as potential gastric cancer subtype-specific biomarkers associated with prognosis. Oncotarget 7 21454-21468. (https://doi.org/10.18632/ oncotarget.7411)

Lei B, Liu S, Qi W, Zhao Y, Li Y, Lin N, Xu X, Zhi C, Mei J, Yan Z, et al. 2013 PBK/TOPK expression in non-small-cell lung cancer: its correlation and prognostic significance with Ki67 and p53 expression. Histopathology 63 696-703. (https://doi.org/10.1111/ his.12215)

Libe R 2015 Adrenocortical carcinoma (ACC): diagnosis, prognosis, and treatment. Frontiers in Cell and Developmental Biology 3 45. (https:// doi.org/10.3389/fcell.2015.00045)

Luo Q, Lei B, Liu S, Chen Y, Sheng W, Lin P, Li W, Zhu H \& Shen H 2014 Expression of PBK/TOPK in cervical cancer and cervical intraepithelial neoplasia. International Journal of Clinical and Experimental Pathology 7 8059-8064.

Matsumoto S, Abe Y, Fujibuchi T, Takeuchi T, Kito K, Ueda N, Shigemoto K \& Gyo K 2004 Characterization of a MAPKK-like protein kinase TOPK. Biochemical and Biophysical Research Communications 325 997-1004. (https://doi.org/10.1016/j. bbrc.2004.10.133)

Matsuo Y, Park JH, Miyamoto T, Yamamoto S, Hisada S, Alachkar H \& Nakamura Y 2014 TOPK inhibitor induces complete tumor regression in xenograft models of human cancer through inhibition of cytokinesis. Science Translational Medicine 6 259ra145. (https://doi. org/10.1126/scitranslmed.3010277)

Mohan DR, Lerario AM \& Hammer GD 2018 Therapeutic targets for adrenocortical carcinoma in the genomics era. Journal of the Endocrine Society 2 1259-1274. (https://doi.org/10.1210/js.2018-00197)

Nandi AK, Ford T, Fleksher D, Neuman B \& Rapoport AP 2007 Attenuation of DNA damage checkpoint by PBK, a novel mitotic kinase, involves protein-protein interaction with tumor suppressor p53. Biochemical and Biophysical Research Communications 358 181-188. (https://doi.org/10.1016/j.bbrc.2007.04.125)

Ohashi T, Komatsu S, Ichikawa D, Miyamae M, Okajima W, Imamura T, Kiuchi J, Nishibeppu K, Kosuga T, Konishi H, et al. 2016 Overexpression of PBK/TOPK contributes to tumor development and poor outcome of esophageal squamous cell carcinoma. Anticancer Research 36 6457-6466. (https://doi.org/10.21873/anticanres.11244)

Ohashi T, Komatsu S, Ichikawa D, Miyamae M, Okajima W, Imamura T, Kiuchi J, Kosuga T, Konishi H, Shiozaki A, et al. 2017 Overexpression of PBK/TOPK relates to tumour malignant potential and poor outcome of gastric carcinoma. British Journal of Cancer 116 218-226. (https://doi.org/10.1038/bjc.2016.394)

Park JH, Lin ML, Nishidate T, Nakamura Y \& Katagiri T 2006 PDZbinding kinase/T-LAK cell-originated protein kinase, a putative cancer/testis antigen with an oncogenic activity in breast cancer. Cancer Research 66 9186-9195. (https://doi.org/10.1158/0008-5472. CAN-06-1601)

Park JH, Nishidate T, Nakamura Y \& Katagiri T 2010 Critical roles of T-LAK cell-originated protein kinase in cytokinesis. Cancer Science 101 403-411. (https://doi.org/10.1111/j.1349-7006.2009.01400.x)

Quinkler M, Hahner S, Wortmann S, Johanssen S, Adam P, Ritter C, Strasburger C, Allolio B \& Fassnacht M 2008 Treatment of advanced adrenocortical carcinoma with erlotinib plus gemcitabine. Journal of Clinical Endocrinology and Metabolism 93 2057-2062. (https://doi. org/10.1210/jc.2007-2564) (c) 2019 Society for Endocrinology Published by Bioscientifica Ltd. Printed in Great Britain 
Rizkallah R, Batsomboon P, Dudley GB \& Hurt MM 2015 Identification of the oncogenic kinase TOPK/PBK as a master mitotic regulator of C2H2 zinc finger proteins. Oncotarget 6 1446-1461. (https://doi. org/10.18632/oncotarget.2735)

Sampaoli C, Cerquetti L, Gawhary RE, Bucci B, Amendola D, Marchese R, Misiti S, Novelli G, Toscano V \& Stigliano A 2012 p53 stabilization induces cell growth inhibition and affects IGF2 pathway in response to radiotherapy in adrenocortical cancer cells. PLOS ONE 7 e45129. (https://doi.org/10.1371/journal.pone.0045129)

Sbiera S, Leich E, Liebisch G, Sbiera I, Schirbel A, Wiemer L, Matysik S, Eckhardt C, Gardill F, Gehl A, et al. 2015 Mitotane inhibits sterol-Oacyl transferase 1 triggering lipid-mediated endoplasmic reticulum stress and apoptosis in adrenocortical carcinoma cells. Endocrinology 156 3895-3908. (https://doi.org/10.1210/en.2015-1367)

Shinde SR, Gangula NR, Kavela S, Pandey V \& Maddika S 2013 TOPK and PTEN participate in CHFR mediated mitotic checkpoint. Cellular Signalling 25 2511-2517. (https://doi.org/10.1016/j. cellsig.2013.08.013)

Stauffer S, Zeng Y, Zhou J, Chen X, Chen Y \& Dong J 2017 CDK1mediated mitotic phosphorylation of PBK is involved in cytokinesis and inhibits its oncogenic activity. Cellular Signalling 39 74-83. (https://doi.org/10.1016/j.cellsig.2017.08.001)
Tentler JJ, Tan AC, Weekes CD, Jimeno A, Leong S, Pitts TM, Arcaroli JJ, Messersmith WA \& Eckhardt SG 2012 Patient-derived tumour xenografts as models for oncology drug development. Nature Reviews: Clinical Oncology 9 338-350. (https://doi.org/10.1038/ nrclinonc.2012.61)

Terzolo M, Daffara F, Ardito A, Zaggia B, Basile V, Ferrari L \& Berruti A 2014 Management of adrenal cancer: a 2013 update. Journal of Endocrinological Investigation 37 207-217. (https://doi.org/10.1007/ s40618-013-0049-2)

Wang T \& Rainey WE 2012 Human adrenocortical carcinoma cell lines. Molecular and Cellular Endocrinology 351 58-65. (https://doi. org/10.1016/j.mce.2011.08.041)

Wang MY, Lin ZR, Cao Y, Zheng LS, Peng LX, Sun R, Meng DF, Xie P, Yang JP, Cao L, et al. 2016 PDZ binding kinase (PBK) is a theranostic target for nasopharyngeal carcinoma: driving tumor growth via ROS signaling and correlating with patient survival. Oncotarget 7 26604-26616. (https://doi.org/10.18632/oncotarget.8445)

Zheng S, Cherniack AD, Dewal N, Moffitt RA, Danilova L, Murray BA, Lerario AM, Else T, Knijnenburg TA, Ciriello G, et al. 2016 Comprehensive pan-genomic characterization of adrenocortical carcinoma. Cancer Cell 29 723-736. (https://doi.org/10.1016/j. ccell.2016.04.002)

Received in final form 11 June 2019

Accepted 17 July 2019

Accepted Preprint published online 17 July 2019 (c) 2019 Society for Endocrinology Published by Bioscientifica Ltd. Printed in Great Britain 